\title{
Respite for hybrid coronary revascularization
}

\author{
Vincent Gacad, Twinkle Singh, Ayush Motwani, Rohan Samson, Thierry H. Le Jemtel \\ Section of Cardiology, Department of Medicine, Tulane University School of Medicine, Tulane University Heart and Vascular \\ Institute, New Orleans, LA 70112, USA.
}

Correspondence to: Dr. Thierry H. Le Jemtel, Section of Cardiology, Department of Medicine, Tulane University School of Medicine, Tulane University Heart and Vascular Institute, New Orleans, LA 70112, USA. E-mail: lejemtel@tulane.edu

How to cite this article: Gacad V, Singh T, Motwani A, Samson R, Le Jemtel TH. Respite for hybrid coronary revascularization. Vessel Plus 2019;3:28. http://dx.doi.org/10.20517/2574-1209.2019.011

Received: 17 Apr 2019 First Decision: 26 Jun 2019 Revised: 15 Jul 2019 Accepted: 30 Jul 2019 Published: 7 Aug 2019

Science Editor: Mario F. L. Gaudino Copy Editor: Cai-Hong Wang Production Editor: Tian Zhang

\begin{abstract}
Hybrid coronary revascularization incorporates a surgical anastomosis of the left internal mammary artery to the left anterior descending coronary artery through a thoracotomy and percutaneous implantation of drug eluting stents in diseased non-left anterior descending coronary arteries. Hybrid coronary artery revascularization can be performed as a 1-stage procedure in a hybrid operating room or as a tightly scheduled 2-stage procedure. Hybrid coronary artery revascularization is seldom the selected modality for coronary revascularization due to the lack of a hybrid operating room in many hospitals, the recommended thoracotomy approach for bypass, or the rigid schedule of surgical and endovascular revascularization. A 2-stage approach, using a sternotomy as compared to standard thoracotomy, and a flexible schedule between surgical and endovascular procedures may facilitate the adoption of hybrid coronary revascularization with noncomplex multi-vessel stable coronary artery disease.
\end{abstract}

Keywords: Hybrid, coronary artery bypass, revascularization, multi-vessel, saphenous vein graft, left anterior mammary artery, percutaneous coronary intervention

\section{INTRODUCTION}

Medical therapy aiming at the stabilization and possibly the reversal of atherosclerosis in patients with stable coronary artery disease (CAD) has steadily progressed over the past 20 years ${ }^{[1-4]}$. However, patients with CAD who remain symptomatic despite optimal anti-anginal therapy or with limited life expectancy due to multi-vessel CAD (mCAD) are candidates for coronary artery revascularization $(\mathrm{CAR})^{[5,6]}$. CAR no longer requires open heart surgery for the implantation of a coronary artery bypass graft (CABG); it 
now can be achieved by percutaneous coronary intervention (PCI) with endovascular implantation of drug eluting stents (DES), which target coronary obstructions that hamper myocardial perfusion during exercise $^{[7-12]}$. The indications, benefits and shortcomings of surgical and endovascular CAR are evolving and a constant source of debate ${ }^{[6,13]}$. However, two aspects of CAR are overwhelmingly agreed on: the left internal mammary artery (LIMA) is the longest-lasting and most event free conduit for CABG and the completeness of CAR is an important determinant of its long-term outcome ${ }^{[14-16]}$.

Due in part to LIMA long-lasting patency, CABG surgery is considered to be the CAR procedure of choice in patients with $\mathrm{mCAD}$ that encompasses the left anterior descending artery (LAD) ${ }^{[17]}$. However while revascularization of non-LAD coronaries is commonly achieved with implantation of saphenous vein grafts (SVG) alongside the LIMA, another treatment option is a staged procedure, referred to as hybrid coronary revascularization (HCR), where revascularization of non-LAD coronaries is achieved by percutaneous implantation of 2 nd generation $\mathrm{DES}^{[18,19]}$. Although it was advocated for $\geq 2$ decades, HCR only represents $<0.5 \%$ of the total of CABG procedures performed ${ }^{[20]}$.

The rationale for HCR and the barriers to its widespread adoption are first discussed. A pragmatic approach to HCR, that may facilitate its adoption by the cardiovascular community, is then advocated.

\section{SAPHENOUS VEIN GRAFT PATENCY}

Autologous saphenous vein was the conduit used by Favaloro in his landmark CABG operation 50 years ago $^{[21]}$. SVG still account for $>80 \%$ of conduits used in CABG surgery ${ }^{[22,23]}$. The rate of SVG occlusions has been estimated be 15\% 1-year post implantation, $1 \%-2 \%$ per year from year 1 to 6 and $4 \%$ per year from year 6 to 10 resulting in a patency rate of $60 \%$ at 10 years ${ }^{[24]}$. More recent data suggests $42.8 \%$ of SVG failure (defined by $\geq 75 \%$ stenosis) at $12-18$ months after CABG surgery in 1828 patients who underwent angiography for clinical reasons or per protocol ${ }^{[25]}$. The rate of SVG failure was similar $12-18$ months implantation in 926 patients enrolled in the Project of EX-Vivo Vein Graft Engineering via Transfection (PREVENT) IV trial ${ }^{[26]}$. The bulk of SVG patency rate data was collected in large volume University or Veterans Administration medical centers when 400,000 CABG operations were performed annually in the United States ${ }^{[27]}$. Nowadays with PCI being the most common procedure for CAR ${ }^{[6]}$, CABG surgery is less performed and the current patency rate of SVG is unknown.

Rapid development of SVG atherosclerosis is the primary reason for the low SVG patency rate 5-10 years after implantation ${ }^{[28]}$. Systemic arterial pressure and harvesting-related trauma cause endothelial damage and intimal hyperplasia. An inflammatory response follows with recruitment of immune cells, activation of pro-thrombotic factors, vascular smooth muscle cells migration and extra cellular matrix degradation ${ }^{[29]}$. Macrophages and foam cells promote the development of necrotic chores that expand and eventually rupture leading to intra vascular thrombosis and clinically full-blown atherosclerosis ${ }^{[24]}$. Due to its diffuse and friable nature, SVG atherosclerosis progresses rapidly and is not mitigated by implantation of DES ${ }^{[28]}$. Further, mobilization of embolic debris and serotonin-induced vasospasm during PCI may result in a noreflow phenomenon and in-stent restenosis ${ }^{[30,31]}$. Targeted therapy at all the steps of the atherosclerosis cascade has failed to alter the progression of atherosclerosis in SVG. Atherosclerosis is diffuse and often concentric involving $90 \%$ to $100 \%$ of the graft circumference ${ }^{[30,32]}$.

Redo revascularization is currently the only therapeutic option for diseased $\mathrm{SVG}^{[31,33]}$, and is seldom achieved by repeat CABG surgery due to technical difficulties and a mortality that is 5 -fold greater than that of the initial operation ${ }^{[34-36]}$. Redo revascularization through PCI with implantation of bare metal stents or DES is also problematic ${ }^{[37-39]}$. Percutaneous interventions on diseased SVG are associated with a highrate of in-stent restenosis, target vessel revascularization, peri-procedural myocardial infarction and inhospital mortality ${ }^{[40,41]}$. Current wisdom advocates to focus revascularization efforts on the native vessel lesions and not on the diseased $\mathrm{SVG}^{[40,41]}$. 


\section{LIMA PATENCY AND OUTCOME}

The LIMA is the conduit used for bypass of a diseased LAD in $95 \%$ of patients who undergo CABG surgery ${ }^{[42]}$. In patients with a LAD obstruction that decreases resting blood flow, the LIMA patency rate is $>90 \%$ at 10 years post implantation ${ }^{[12,43]}$. Failure of LIMA graft mostly occurs in patients with competitive flow between the LIMA and the native vessel as the result of low grade LAD lesion. The long-term patency of a LIMA graft to a diseased LAD guarantees normal perfusion to $\geq 50 \%$ of the total myocardial mass for many years ${ }^{[17,44,45]}$. In contrast to DES that only remedy a single focal LAD obstruction, a LIMA graft protects proximal and mid segments of the LAD against the development of new atherosclerotic lesions ${ }^{[46-48]}$. Further, by restoring normal LAD blood flow at rest and during exercise a LIMA graft enhances downstream vascular endothelial function and thereby delays the progression of atherosclerosis $^{[47]}$. The LIMA endothelium is abundant in inducible nitric oxide (NO) synthase and thereby has a high NO concentration. The LIMA endothelium prevents graft thrombosis, slows the progression of target vessel atherosclerosis and maintains distal vessel patency ${ }^{[46,48]}$.

Observational rather than evidence-based data led to the overwhelming use of LIMA in CABG surgery ${ }^{[49-51]}$. In the absence of evidence based data, one can only speculate on the role that the LIMA plays in the superiority of CABG surgery over PCI with 2nd generation DES in patients with complex $\mathrm{mCAD}^{[47,52,53]}$. The absence of LIMA was found to be associated with redo operation and high mortality in patients after CABG surgery ${ }^{[14,54]}$.

In summary, despite a lack of evidence-based data, the LIMA to LAD bypass graft is largely thought to underlie the long-lasting and favorable outcome of contemporary CABG surgery.

\section{DES}

CABG surgery is rarely performed without implantation of a LIMA graft. Thus, the outcome of patients who undergo surgical revascularization with only SVG cannot be compared to that of patients who undergo PCI revascularization with current 2nd generation DES. In the absence of evidence-based data comparing the effects of SVG vs. DES on outcome measures, data must be compared from findings of individual therapeutic trials of these different CAR modalities ${ }^{[55]}$. The incidence of in-stent thrombosis (ST) and SVG occlusions was similar at 5 years with 1st generation DES like the paclitaxel eluting stent (PES) in the SYNTAX trial ${ }^{[56]}$. Advancements of stent technology, with the development of everolimus eluting stent (EES), have provided improvements in immediate 1 -year ST rate $(0.60 \% \text { vs. } 1.59 \%)^{[57]}$ and 5 -year ST rate $(1.30 \% \text { vs. } 1.86 \%)^{[16]}$ when compared to first-generation DES. However, as ST exerts a greater effect on mortality than SVG occlusion ${ }^{[56]}$, ischemia-driven target lesion revascularization (ID-TLR) may be a more apt comparison with SVG graft failure. In a meta-analysis from 2016, 5-year ID-TLR incidence was 7.53\% with EES and $11.50 \%$ with $\mathrm{PES}^{[58]}$, which is favorable compared to a $75 \%-86 \%$ patency for SVG in 5-7 years ${ }^{[42]}$ [Table 1].

In summary we do not have randomized trials of surgical CAR with exclusive implantation of SVG vs. PCI endovascular revascularization with implantation of 2nd generation DES. Therapeutic trials of these 2 CAR modalities point to similar patency rate and outcome with SVG and 2nd generation DES at 5 years.

\section{MULTI-VESSEL REVASCULARIZATION IN ACUTE CORONARY SYNDROME}

Acute coronary syndrome, with its spectrum in disease from unstable angina to ST-elevation myocardial infarction (STEMI), portends future repeat cardiovascular events ${ }^{[59]}$. CABG in STEMI is very rare, comprising about $5 \%-8 \%$ of STEMI presentations in the ACTION registry per year ${ }^{[60]}$; $39 \%$ of those CABG cases were after primary PCI and median angiogram-to-CABG time was $23.3 \mathrm{~h}$. Numerous studies have shown a correlation between total ischemia time and overall cardiovascular mortality in STEMI ${ }^{[61-63]}$. 
Table 1. Rates of drug eluting stent target lesion revascularization', saphenous vein graft failure ${ }^{2}$, and LIMA-LAD arterial graft failure ${ }^{2}$

\begin{tabular}{llll}
\hline & 1-year & 5-year & 10-year \\
\hline 1st generation DES- Paclitaxel (PES)/Sirolimus (SES) & $3.97 \%^{3}$ & $11.50 \%^{4}$ & $16.4 \%^{6}$ \\
2nd generation DES- Everolimus (EES) & $6.03 \%^{3}$ & $7.53 \%{ }^{4}$ & $14.8 \%^{6}$ \\
Saphenous vein graft & $2.1 \%-19 \%^{5}$ & $14 \%-25 \%^{5}$ & $39 \%^{8}$ \\
LIMA-LAD graft & $3.4 \%^{7}$ & $11.9 \%{ }^{7}$ & $11.9 \%^{7}$ \\
\hline
\end{tabular}

${ }^{1}$ Drug eluting stent occlusion was measured by rates of target lesion revascularization; ${ }^{2}$ saphenous vein graft patency was measured by angiographic evidence of vessel occlusion; ${ }^{3}$-year data from a meta-analysis comparing 1st generation DES (PES and SES) to 2 nd generation DES (EES) ${ }^{[57]} ;{ }^{4} 5$-year data from a meta-analysis comparing 1 st generation DES (PES) to 2 nd generation DES (EES) ${ }^{[16]} ;{ }^{5} 1$ year and 5-year data from a meta-analysis comparing saphenous vein $v s$. arterial conduits ${ }^{[42]}$. It should be noted that definitions of graft failure varied between the different studies; ${ }^{6} 10$-year data from a multicenter European randomized trial, which used pre-planned repeat angiography to reassess in-stent restenosis ${ }^{[86]} ;{ }^{7,8}$ rates of SVG and LIMA-LAD were determined via angiography in their respective studies $^{[15,87]}$

As an attempt to reduce ischemic time and practical considerations of immediate revascularization after a diagnostic angiogram, PCI has become the most frequent revascularization strategy ${ }^{[64]}$. There is a scarcity of data directly comparing DES with CABG in the setting of ACS, which mostly consists of subgroup analysis of larger PCI vs. CABG studies. A recent meta-analysis of these subgroups found reduced myocardial infarction (MI) incidence with CABG (3.8\%) when compared to DES (7.5\%) after non-ST elevation MI (NSTEMI), with similar rates of mortality $(8.7 \%$ vs. $10.8 \%, P=0.248)$ and stroke $(2.6 \% v \text { s. } 2.8 \%, P=0.788)^{[65]}$.

Recent PCI mortality data have favored immediate complete revascularization (the coronary intervention of both culprit and non-culprit obstructive stenoses) rather than culprit-lesion only PCI followed by staged-PCI of non-critical stenosis ${ }^{[6,67]}$. When compared to culprit-only PCI, complete revascularization has shown similar rates of contrast-induced nephropathy ${ }^{[68]}$.

In summary, revascularization methods in the setting of acute coronary syndrome skew toward PCI in part due mortality benefit from decreased ischemic time. However, in head-to-head analysis there is a modest reduced subsequent $\mathrm{MI}$ benefit for CABG.

\section{CONVENTIONAL HCR}

HCR consists of 2 separate procedures: surgical CABG surgery with a LIMA graft to the LAD and PCI with implantation of 2 nd generation DES to diseased non-LAD coronary arteries. The 2 procedures can be performed back to back in a 1-stage approach or on different days in a 2-stage approach [Table 2 and Figure 1].

The 1-stage approach is generally performed in a hybrid operating room (OR) with the LIMA graft being first anastomosed to the LAD followed by PCI with endovascular implantation of 2nd generation DES in non-LAD arteries ${ }^{[19,69-71]}$. The surgical LIMA to LAD surgical anastomosis is commonly performed through an anterolateral thoracotomy at the level of the 4-5th intercostal space. The thoracotomy approach has the advantage of shorter ventilation time and post-operative length of stay over a conventional CABG sternotomy ${ }^{[72-75]}$. However, thoracotomy may be associated with increased pain levels in the immediate post-operative period ${ }^{[70,76]}$. The use of cardiopulmonary bypass is commonly left to operator preference. Percutaneous endovascular revascularization of diseased non-LAD arteries is performed after administration of loading dose of anti-platelet agents ${ }^{[20]}$. The advantage of the 1-stage approach is the verification and possible repair of a defective LIMA-LAD anastomosis before initiation of anti-platelet therapy. Its disadvantage is the need for a hybrid OR.

The 2-stage approach encompasses an interval of 1-2 days between surgical and endovascular CAR ${ }^{[71]}$. It allows for control of bleeding in the post-operative period before initiation of anti-platelet therapy and does 
Table 2. 1-Stage vs, 2-stage hybrid coronary revascularization

\begin{tabular}{|c|c|c|}
\hline & 1-stage & 2-stage \\
\hline Advantages & $\begin{array}{l}\text { Gives option for off-pump LIMA-LAD bypass, can avoid a } \\
\text { median sternotomy by using thoracotomy with minimally } \\
\text { invasive/endoscopic/robotic techniques, shorter ventilation } \\
\text { and hospital time, verification and correction of LIMA-LAD } \\
\text { grafts prior to antiplatelet therapy induction }\end{array}$ & $\begin{array}{l}\text { Does not require hybrid operating room, increased } \\
\text { time for prevention of post-operative bleeding, } \\
\text { decreased inflammatory response to bypass } \\
\text { surgery that may cause in-stent thrombosis, } \\
\text { provide option for } \mathrm{PCl} \text {-first of non-LAD lesions to } \\
\text { avoid ischemia or infarction in those territories } \\
\text { during LIMA-LAD surgery }\end{array}$ \\
\hline Disadvantages & $\begin{array}{l}\text { High cost, long operating time, requirement of hybrid } \\
\text { operating room, increased coordination requirement } \\
\text { between interventional cardiologist and cardiothoracic } \\
\text { surgeon, thoracotomy option has increased pain }\end{array}$ & $\begin{array}{l}\text { Increased inpatient admission time, no option } \\
\text { for immediate repair of defective LIMA-LAD } \\
\text { anastomosis, increased bleeding risk for PCl-first } \\
\text { approach }\end{array}$ \\
\hline
\end{tabular}

LIMA: left internal mammary artery; LAD: left anterior descending; PCI: percutaneous coronary intervention

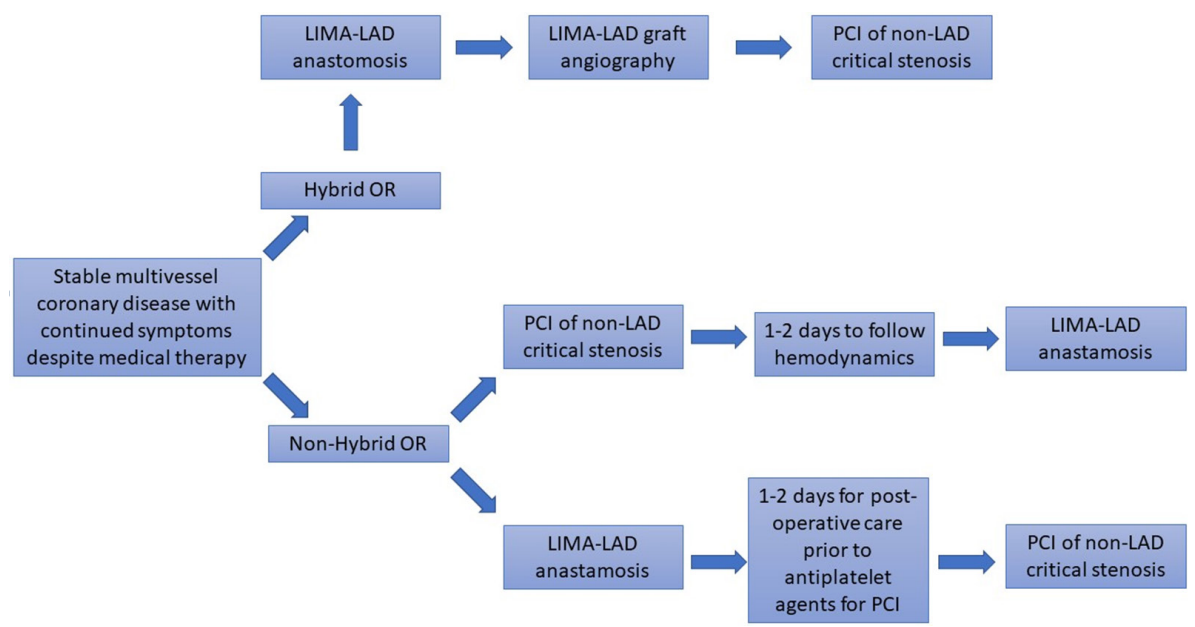

Figure 1. Hybrid Coronary Revascularization process flow-chart. This flow-chart details the steps of Hybrid Coronary Revascularization for both hybrid OR and non-hybrid OR settings. In LIMA-LAD anastomosis can be through mini-thoracotamy or sternotomy. In the hybridOR 1-step approcach, LIMA-LAD graft can be immediately visualized with angiography. OR: operating room; LIMA: left internal mammary artery; LAD: left anterior descending; PCl: percutaneous coronary intervention

not require a hybrid OR. When patients have critical lesions of non-LAD arteries, PCI with endovascular implantation of 2nd generation DES in diseased non-LAD arteries can be first performed to avoid complications (hypotension and hemodynamic compromise) at the times of thoracotomy and the LIMA graft to the $\mathrm{LAD}^{[77]}$. The PCI endovascular revascularization first approach increases the risk of bleeding as CABG surgery is then performed in patients who are receiving dual anti-platelet therapy ${ }^{[77]}$.

\section{HCR IN CLINICAL PRACTICE}

Given the complex multi-disciplinary nature of HCR and its pre-procedural planning, its clinical utility would be in the treatment of stable ischemic heart disease with refractory angina [Figure 2]. Coronary physiologic assessments such as fractional flow reserve ${ }^{[78]}$ have shown benefit in selecting a subset of patients who may benefit from PCI when compared to medical management. At this time there is no current data for potential use in acute coronary syndrome, but that may change over time with the increasing number of hybrid ORs and multi-disciplinary heart teams. HCR allows for a less invasive approach than traditional CABG, while providing added mortality/graft patency benefit of the LIMA-LAD over the multi-vessel PCI with DES ${ }^{[79-81]}$. 


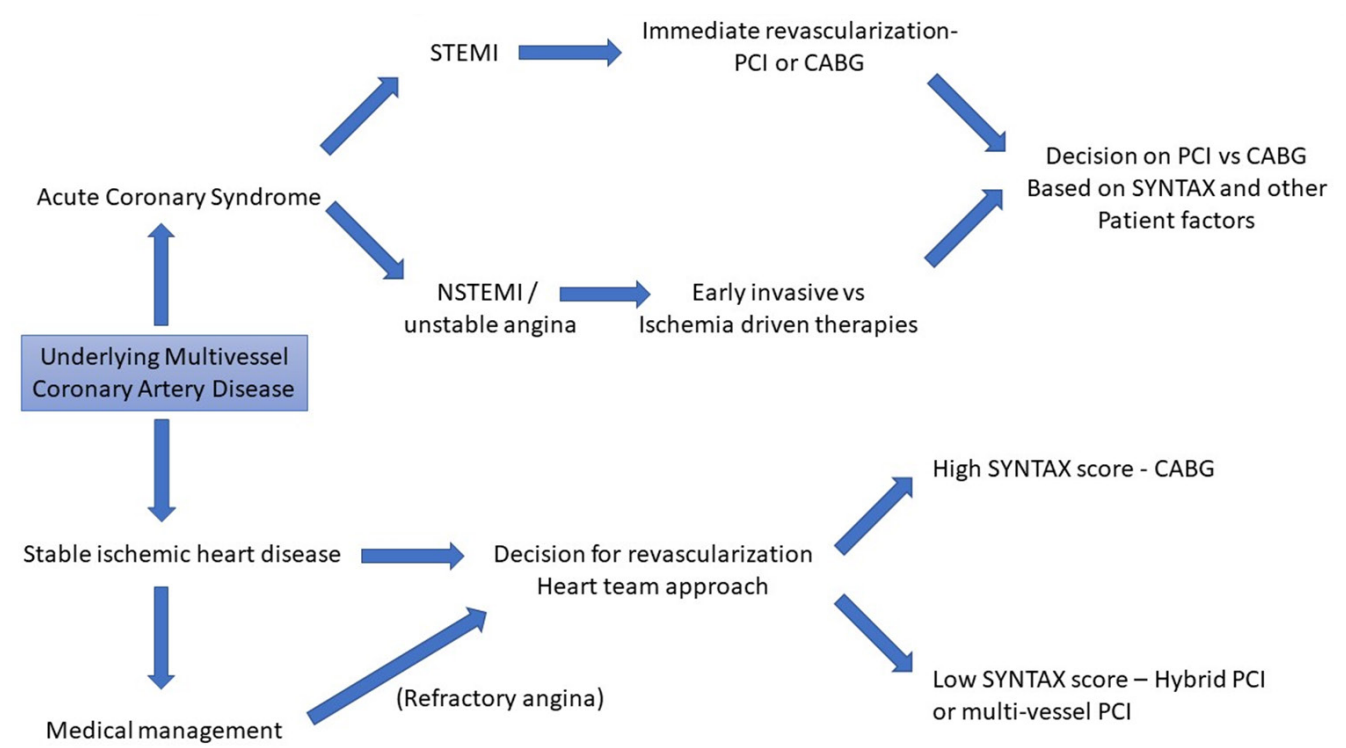

Figure 2. A proposed clinical-decision making flowchart with Hybrid Coronary Revascularization implementation. PCI: percutaneous coronary intervention; CABG: coronary artery bypass graft; STEMI: ST-elevation myocardial infarction; NSTEMI: non-ST elevation myocardial infarction

\section{PRAGMATIC HCR}

The 1-stage approach to conventional HCR requires a hybrid OR that is only available in one third of hospitals in the United States ${ }^{[20]}$. The 1-stage approach also requires a close collaboration between interventional cardiologists and cardio-thoracic surgeons. Such collaboration is common for a transcatheter aortic valve implantation procedure but is not common practice for the management of CAD patients $^{[82]}$. The major aim of HCR is to provide CAD patients with the long-lasting beneficial outcome that LIMA affords and the complete revascularization including attention to chronic total occlusion that endovascular stenting allows ${ }^{[33-85]}$.

HCR is a most suited form of revascularization for patients with mCAD and low to intermediate SYNTAX score. Patients with mCAD and high SYNTAX score are better served by CABG surgery with implantation of multi arterial conduits and when needed $\mathrm{SVG}^{[12]}$. A more pragmatic approach to HCR than that underlined in above-mentioned protocols is likely to facilitate its adoption by interventional cardiologists and cardio-thoracic surgeons. The 2-stage approach to HCR appears to be eminently more practical than the 1-stage approach in most American medical centers. CABG of LIMA to LAD may be conveniently performed through sternotomy as CT surgeons are more familiar with the sternotomy than the thoracotomy approach for CABG. An interval of 2-3 days between surgical and endovascular revascularization allows times for the inflammatory response to surgery to subside and for control of perioperative bleeding before initiation of dual anti-platelet therapy. The 1-stage approach to HCR and the practice of HCR in patients with critical obstructions of non-LAD arteries will await encouraging results of the 2-stage approach to HCR.

\section{CONCLUSION}

In the age of PCI, HCR combines the known benefit of LIMA to LAD grafting with the minimally invasive approach of stenting non-LAD territories. The wide acceptance of HCR by the cardiovascular community will require demonstration of safety and long-lasting benefit on cardiovascular outcomes. A more pragmatic approach than currently outlined may help interventional cardiologists and cardiothoracic surgeons gain experience with dual surgical/endovascular coronary revascularization. 


\section{DECLARATIONS}

\section{Authors' contributions}

Concept and design: Gacad V, Singh T, Motwani A, Samson R, Le Jemtel TH

Data acquisition: Gacad V, Singh T, Motwani A

Data analysis: Gacad V, Singh T, Motwani A

Manuscript preparation: Gacad V, Singh T, Motwani A

Critical revision and finalizing of the manuscript: Gacad V, Singh T, Motwani A, Samson R, Le Jemtel TH

\section{Availability of data and materials}

Not applicable.

\section{Financial support and sponsorship}

None.

\section{Conflicts of interest}

All authors declared that there are no conflicts of interest.

\section{Ethical approval and consent to participate}

Not applicable.

\section{Consent for publication}

Not applicable.

\section{Copyright}

(C) The Author(s) 2019.

\section{REFERENCES}

1. Koskinas KC, Windecker S, Räber L. Regression of coronary atherosclerosis: current evidence and future perspectives. Trends Cardiovasc Med 2016;26:150-61.

2. Nissen SE, Tuzcu EM, Schoenhagen P, Brown BG, Ganz P, et al. Effect of intensive compared with moderate lipid-lowering therapy on progression of coronary atherosclerosis: a randomized controlled trial. JAMA 2004;291:1071-80.

3. Nissen SE, Nicholls SJ, Sipahi I, Libby P, Raichlen JS, et al. Effect of very high-intensity statin therapy on regression of coronary atherosclerosis: the ASTEROID trial. JAMA 2006;295:1556-65.

4. Nicholls SJ, Ballantyne CM, Barter PJ, Chapman MJ, Erbel RM, et al. Effect of two intensive statin regimens on progression of coronary disease. N Engl J Med 2011;365:2078-87.

5. VA Coronary Artery Bypass Surgery Cooperative Study Group. Eighteen-year follow-up in the veterans affairs cooperative study of coronary artery bypass surgery for stable angina. Circulation 1992;86:121-30.

6. Fihn SD, Gardin JM, Abrams J, Berra K, Blankenship JC, et al. 2012ACCF/AHA/ACP/AATS/PCNA/SCAI/STS guideline for the diagnosis and management of patients with stable ischemic heart disease: a report of the American College of Cardiology Foundation/ American Heart Association Task Force on, American Association for Thoracic Surgery, Preventive Cardiovascular Nurses Association, Society for Cardiovascular Angiography and Interventions, and Society of Thoracic Surgeons. J Am Coll Cardiol 2012;60:e44-164.

7. Serruys PW, Ong AT, van Herwerden LA, Sousa JE, Jatene A, et al. Five-year outcomes after coronary stenting versus bypass surgery for the treatment of multivessel disease: the final analysis of the Arterial Revascularization Therapies Study (ARTS) randomized trial. J Am Coll Cardiol 2005;46:575-81.

8. Park SJ, Ahn JM, Kim YH, Park DW, Yun SC, et al. Trial of everolimus-eluting stents or bypass surgery for coronary disease. N Engl J Med 2015;372:1204-12.

9. Kapur A, Hall RJ, Malik IS, Qureshi AC, Butts J, et al. Randomized comparison of percutaneous coronary intervention with coronary artery bypass grafting in diabetic patients. 1-year results of the CARDia (Coronary Artery Revascularization in Diabetes) trial. J Am Coll Cardiol 2010;55:432-40.

10. Farkouh ME, Domanski M, Sleeper LA, Siami FS, Dangas G, et al. Strategies for multivessel revascularization in patients with diabetes. N Engl J Med 2012;367:2375-84.

11. Hueb W, Lopes NH, Gersh BJ, Soares P, Machado LA, et al. Five-year follow-up of the Medicine, Angioplasty, or Surgery Study (MASS 
II): a randomized controlled clinical trial of 3 therapeutic strategies for multivessel coronary artery disease. Circulation 2007;115:1082-9.

12. Serruys PW, Morice MC, Kappetein AP, Colombo A, Holmes DR, et al. Percutaneous coronary intervention versus coronary-artery bypass grafting for severe coronary artery disease. N Engl J Med 2009;360:961-72.

13. Hou L, Ghosh B, Hakeem A. A physiological approach to refine appropriateness of revascularization, clinical decision making and prognosis in patients with multi vessel coronary artery disease. J Thorac Dis 2018;10:5661-5.

14. Mehta RH, Honeycutt E, Shaw LK, Milano CA, Smith PK, et al. Clinical and angiographic correlates of short- and long-term mortality in patients undergoing coronary artery bypass grafting. Am J Cardiol 2007;100:1538-42.

15. Goldman S, Zadina K, Moritz T, Ovitt T, Sethi G, et al. Long-term patency of saphenous vein and left internal mammary artery grafts after coronary artery bypass surgery: results from a Department of Veterans Affairs Cooperative Study. J Am Coll Cardiol 2004;44:2149-56.

16. Meng M, Gao B, Wang X, Bai ZG, Sa RN, et al. Long-term clinical outcomes of everolimus-eluting stent versus paclitaxel-eluting stent in patients undergoing percutaneous coronary interventions: a meta-analysis. BMC Cardiovasc Disord 2016;16:34.

17. Mehta RH, Honeycutt E, Peterson ED, Granger CB, Halabi AR, et al. Impact of internal mammary artery conduit on long-term outcomes after percutaneous intervention of saphenous vein graft. Circulation 2006;114:1396-401.

18. Saha T, Naqvi SY, Goldberg S. Hybrid revascularization: a review. Cardiology 2018;140:35-44.

19. Gąsior M, Zembala MO, Tajstra M, Filipiak K, Gierlotka M, et al. Hybrid revascularization for multivessel coronary artery disease. JACC Cardiovasc Interv 2014;7:1277-83.

20. Harskamp RE, Brennan JM, Xian Y, Halkos ME, Puskas JD, et al. Practice patterns and clinical outcomes after hybrid coronary revascularization in the United States: an analysis from the society of thoracic surgeons adult cardiac database. Circulation 2014;130:872-9.

21. Squiers JJ, Mack MJ. Coronary artery bypass grafting-fifty years of quality initiatives since Favaloro. Ann Cardiothorac Surg 2018;7:516-20.

22. Head SJ, Milojevic M, Taggart DP, Puskas JD. Current practice of state-of-the-art surgical coronary revascularization. Circulation 2017;136:1331-45.

23. Gaudino M, Mack MJ, Taggart DP. Additional arterial conduits in coronary artery bypass surgery: finally coming of age. J Thorac Cardiovasc Surg 2018;156:541-3.

24. Motwani JG, Topol EJ. Aortocoronary saphenous vein graft disease: pathogenesis, predisposition, and prevention. Circulation 1998;97:916-31.

25. Hess CN, Lopes RD, Gibson CM, Hager R, Wojdyla DM, et al. Saphenous vein graft failure after coronary artery bypass surgery: insights from PREVENT IV. Circulation 2014;130:1445-51.

26. Alexander JH, Hafley G, Harrington RA, Peterson ED, Ferguson TB Jr, et al. Efficacy and safety of edifoligide, an E2F transcription factor decoy, for prevention of vein graft failure following coronary artery bypass graft surgery: PREVENT IV: a randomized controlled trial. JAMA 2005;294:2446-54.

27. Alexander JH, Smith PK. Coronary-artery bypass grafting. N Engl J Med 2016;374:1954-64.

28. Hindnavis V, Cho SH, Goldberg S. Saphenous vein graft intervention: a review. J Invasive Cardiol 2012;24:64-71.

29. Yahagi K, Kolodgie FD, Otsuka F, Finn AV, Davis HR, et al. Pathophysiology of native coronary, vein graft, and in-stent atherosclerosis. Nat Rev Cardiol 2016;13:79-98.

30. Sarjeant JM, Rabinovitch M. Understanding and treating vein graft atherosclerosis. Cardiovasc Pathol 2002;11:263-71.

31. Lee M, Kong J. Current state of the art in approaches to saphenous vein graft interventions. Interv Cardiol 2017;12:85-91.

32. Davlouros P, Damelou A, Karantalis V, Xanthopoulou I, Mavronasiou E, et al. Evaluation of culprit saphenous vein graft lesions with optical coherence tomography in patients with acute coronary syndromes. JACC Cardiovasc Interv 2011;4:683-93.

33. Brilakis ES, de Lemos JA, Cannon CP, Wiviott SD, Murphy SA, et al. Outcomes of patients with acute coronary syndrome and previous coronary artery bypass grafting (from the Pravastatin or Atorvastatin Evaluation and Infection Therapy [PROVE IT-TIMI 22] and the Aggrastat to Zocor [A to Z] trials). Am J Cardiol 2008;102:552-8.

34. Christenson JT, Simonet F, Badel P, Schmuziger M. Evaluation of preoperative intra-aortic balloon pump support in high risk coronary patients. Eur J Cardiothorac Surg 1997;11:1097-103; discussion 1104.

35. Morrison DA, Sethi G, Sacks J, Henderson WG, Grover F, et al. Percutaneous coronary intervention versus coronary artery bypass graft surgery for patients with medically refractory myocardial ischemia and risk factors for adverse outcomes with bypass: a multicenter, randomized trial. Investigators of the Department of Veterans Affairs Cooperative Study \#385, the Angina With Extremely Serious Operative Mortality Evaluation (AWESOME). J Am Coll Cardiol 2001;38:143-9.

36. Fitzgibbon GM, Kafka HP, Leach AJ, Keon WJ, Hooper GD, et al. Coronary bypass graft fate and patient outcome: angiographic follow-up of 5,065 grafts related to survival and reoperation in 1,388 patients during 25 years. J Am Coll Cardiol 1996;28:616-26.

37. Morrison DA, Sethi G, Sacks J, Henderson WG, Grover F, et al. Percutaneous coronary intervention versus coronary bypass graft surgery for patients with medically refractory myocardial ischemia and risk factors for adverse outcomes with bypass: the VA AWESOME multicenter registry: comparison with the randomized clinical trial. J Am Coll Cardiol 2002;39:266-73.

38. Almomani A, Pothineni NV, Edupuganti M, Payne J, Agarwal S, et al. Outcomes of fractional flow reserve-based deferral in saphenous vein graft narrowing. Am J Cardiol 2018;122:723-8.

39. Mehilli J. The VELETI II Trial (Sealing Moderate Coronary Saphenous Vein Graft Lesions With Paclitaxel-Eluting Stents): local mechanical intervention fails to stop atheroprogression in saphenous vein grafts. Circ Cardiovasc Interv 2016;9.

40. Mehilli J, Pache J, Abdel-Wahab M, Schulz S, Byrne RA, et al. Drug-eluting versus bare-metal stents in saphenous vein graft lesions 
(ISAR-CABG): a randomised controlled superiority trial. Lancet 2011;378:1071-8.

41. Brilakis ES, Banerjee S, Burke MN. A new treatment strategy for saphenous vein graft lesions?: Letting it Go. J Am Coll Cardiol 2018;71:1983-5.

42. Gaudino M, Antoniades C, Benedetto U, Deb S, Di Franco A, et al. Mechanisms, consequences, and prevention of coronary graft failure. Circulation 2017;136:1749-64.

43. Avgerinos DV, Charitakis K. Hybrid coronary revascularization: present and future. Hellenic J Cardiol 2015;56:193-6.

44. Davies MJ. The pathology of myocardial ischaemia. J Clin Pathol Suppl (R Coll Pathol) 1977;11:45-52.

45. Puskas JD, Halkos ME, DeRose JJ, Bagiella E, Miller MA, et al. Hybrid coronary revascularization for the treatment of multivessel coronary artery disease: a multicenter observational study. J Am Coll Cardiol 2016;68:356-65.

46. Otsuka F, Yahagi K, Sakakura K, Virmani R. Why is the mammary artery so special and what protects it from atherosclerosis? Ann Cardiothorac Surg 2013;2:519-26.

47. Zhang M, Guddeti RR, Matsuzawa Y, Sara JD, Kwon TG, et al. Left internal mammary artery versus coronary stents: impact on downstream coronary stenoses and conduit patency. J Am Heart Assoc 2016;5.

48. Kitamura S. Physiological and metabolic effects of grafts in coronary artery bypass surgery. Circ J 2011;75:766-72.

49. ElBardissi AW, Aranki SF, Sheng S, O'Brien SM, Greenberg CC, et al. Trends in isolated coronary artery bypassgrafting: an analysis of the Society of Thoracic Surgeons adult cardiac surgery database. J Thorac Cardiovasc Surg 2012;143:273-81.

50. Hlatky MA, Boothroyd DB, Reitz BA, Shilane DA, Baker LC, et al. Adoption and effectiveness of internal mammary artery grafting in coronary artery bypass surgery among Medicare beneficiaries. J Am Coll Cardiol 2014;63:33-9.

51. Tabata M, Grab JD, Khalpey Z, Edwards FH, O’Brien SM, et al. Prevalence and variability of internal mammary artery graft use in contemporary multivessel coronary artery bypass graft surgery: analysis of the Society of Thoracic Surgeons National Cardiac Database. Circulation 2009;120:935-40.

52. Diegeler A, Thiele H, Falk V, Hambrecht R, Spyrantis N, et al. Comparison of stenting with minimally invasive bypass surgery for stenosis of the left anterior descending coronary artery. N Engl J Med 2002;347:561-6.

53. Bhatt DL. CABG the clear choice for patients with diabetes and multivessel disease. Lancet 2018;391:913-4.

54. Cosgrove DM, Loop FD, Lytle BW, Gill CC, Golding LA, et al. Predictors of reoperation after myocardial revascularization. J Thorac Cardiovasc Surg 1986;92:811-21.

55. Head SJ, Milojevic M, Daemen J, Ahn JM, Boersma E, et al. Mortality after coronary artery bypass grafting versus percutaneous coronary intervention with stenting for coronary artery disease: a pooled analysis of individual patient data. Lancet 2018;391:939-48.

56. Farooq V, Serruys PW, Zhang Y, Mack M, Ståhle E, et al. Short-term and long-term clinical impact of stent thrombosis and graft occlusion in the SYNTAX trial at 5 years: synergy between percutaneous coronary intervention with taxus and cardiac surgery trial. J Am Coll Cardiol 2013;62:2360-9.

57. Cassese S, Piccolo R, Galasso G, De Rosa R, Piscione F. Twelve-month clinical outcomes of everolimus-eluting stent as compared to paclitaxel- and sirolimus-eluting stent in patients undergoing percutaneous coronary interventions. A meta-analysis of randomized clinical trials. Int J Cardiol 2011;150:84-9.

58. Onuma Y, Miquel-Hebert K, Serruys PW, Investigators SI. Five-year long-term clinical follow-up of the XIENCE V everolimuseluting coronary stent system in the treatment of patients with de novo coronary artery disease: the SPIRIT II trial. EuroIntervention 2013;8:1047-51.

59. Mozaffarian D, Benjamin EJ, Go AS, Arnett DK, Blaha MJ, et al. Heart disease and stroke statistics-2016 update: a report from the American Heart Association. Circulation 2016;133:e38-360.

60. Pi Y, Roe MT, Holmes DN. Utilization, Characteristics, and In-Hospital Outcomes of Coronary Artery Bypass Grafting in Patients With ST-Segment-Elevation Myocardial Infarction: Results From the National Cardiovascular Data Registry Acute Coronary Treatment and Intervention Outcomes Network Registry-Get With The Guidelines. Circ Cardiovasc Qual Outcomes 2017;10.

61. Deeik RK, Schmitt TM, Ihrig TG, Sugimoto JT. Appropriate timing of elective coronary artery bypass graft surgery following acute myocardial infarction. Am J Surg 1998;176:581-5.

62. Lee DC, Oz MC, Weinberg AD, Ting W. Appropriate timing of surgical intervention after transmural acute myocardial infarction. J Thorac Cardiovasc Surg 2003;125:115-9; discussion 119.

63. Parikh SV, de Lemos JA, Jessen ME, Brilakis ES, Ohman EM, et al. Timing of in-hospital coronary artery bypass graft surgery for non-ST-segment elevation myocardial infarction patients results from the National Cardiovascular Data Registry ACTION RegistryGWTG (Acute Coronary Treatment and Intervention Outcomes Network Registry-Get With The Guidelines). JACC Cardiovasc Interv 2010;3:419-27.

64. Thomas MP, Bates ER. Update on primary PCI for patients with STEMI. Trends Cardiovasc Med 2017;27:95-102.

65. Chang M, Lee CW, Ahn JM, Cavalcante R, Sotomi Y, et al. Comparison of outcome of coronary artery bypass grafting versus drugeluting stent implantation for non-ST-elevation acute coronary syndrome. Am J Cardiol 2017;120:380-6.

66. Engstrøm T, Kelbæk H, Helqvist S, Høfsten DE, Kløvgaard L, et al. Complete revascularisation versus treatment of the culprit lesion only in patients with ST-segment elevation myocardial infarction and multivessel disease (DANAMI-3-PRIMULTI): an open-label, randomised controlled trial. Lancet 2015;386:665-71.

67. Zimarino M, Ricci F, Romanello M, Di Nicola M, Corazzini A, et al. Complete myocardial revascularization confers a larger clinical benefit when performed with state-of-the-art techniques in high-risk patients with multivessel coronary artery disease: a meta-analysis of randomized and observational studies. Catheter Cardiovasc Interv 2016;87:3-12. 
68. Chatterjee S, Kundu A, Mukherjee D, Sardar P, Mehran R, et al. Risk of contrast-induced acute kidney injury in ST-elevation myocardial infarction patients undergoing multi-vessel intervention-meta-analysis of randomized trials and risk prediction modeling study using observational data. Catheter Cardiovasc Interv 2017;90:205-12.

69. Rosenblum JM, Harskamp RE, Hoedemaker N, Walker P, Liberman HA, et al. Hybrid coronary revftascularization versus coronary artery bypass surgery with bilateral or single internal mammary artery grafts. J Thorac Cardiovasc Surg 2016;151:1081-9.

70. Kon ZN, Brown EN, Tran R, Joshi A, Reicher B, et al. Simultaneous hybrid coronary revascularization reduces postoperative morbidity compared with results from conventional off-pump coronary artery bypass. J Thorac Cardiovasc Surg 2008;135:367-75.

71. Reicher B, Poston RS, Mehra MR, Joshi A, Odonkor P, et al. Simultaneous "hybrid" percutaneous coronary intervention and minimally invasive surgical bypass grafting: feasibility, safety, and clinical outcomes. Am Heart J 2008;155:661-7.

72. Giambruno V, Jones P, Khaliel F, Chu MW, Teefy P, et al. Hybrid coronary revascularization versus on-pump coronary artery bypass grafting. Ann Thorac Surg 2018;105:1330-5.

73. Song Z, Shen L, Zheng Z, Xu B, Xiong H, et al. One-stop hybrid coronary revascularization versus off-pump coronary artery bypass in patients with diabetes mellitus. J Thorac Cardiovasc Surg 2016;151:1695-701.e1691.

74. Kayatta MO, Halkos ME, Puskas JD. Hybrid coronary revascularization for the treatment of multivessel coronary artery disease. Ann Cardiothorac Surg 2018;7:500-5.

75. Bonatti J, Schachner T, Bonaros N, Lehr EJ, Zimrin D, et al. Robotically assisted totally endoscopic coronary bypass surgery. Circulation 2011;124:236-44.

76. Diegeler A, Walther T, Metz S, Falk V, Krakor R, et al. Comparison of MIDCAP versus conventional CABG surgery regarding pain and quality of life. Heart Surg Forum 1999;2:290-5; discussion 295-6.

77. Verhaegh AJ, Accord RE, van Garsse L, Maessen JG. Hybrid coronary revascularization as a safe, feasible, and viable alternative to conventional coronary artery bypass grafting: what is the current evidence?. Minim Invasive Surg 2013;2013:142616.

78. De Bruyne B, Pijls NH, Kalesan B, Barbato E, Tonino PA, et al. Fractional flow reserve-guided PCI versus medical therapy in stable coronary disease. N Engl J Med 2012;367:991-1001.

79. Green KD, Lynch DR Jr, Chen TP, Zhao D. Combining PCI and CABG: the role of hybrid revascularization. Curr Cardiol Rep 2013;15:351.

80. Serruys PW, Morice MC, Kappetein AP, Colombo A, Holmes DR, et al. Percutaneous coronary intervention versus coronary-artery bypass grafting for severe coronary artery disease. N Engl J Med 2009;360:961-72.

81. BARI Investigators. The final 10-year follow-up results from the BARI randomized trial. J Am Coll Cardiol 2007;49:1600-6.

82. Head SJ, Kaul S, Mack MJ, Serruys PW, Taggart DP, et al. The rationale for Heart Team decision-making for patients with stable, complex coronary artery disease. Eur Heart J 2013;34:2510-8.

83. Azzalini L, Torregrossa G, Puskas JD, Brilakis ES, Lombardi WL, et al. Percutaneous revascularization of chronic total occlusions: rationale, indications, techniques, and the cardiac surgeon's point of view. Int J Cardiol 2017;231:90-6.

84. Escaned J, Collet C, Ryan N, De Maria GL, Walsh S, et al. Clinical outcomes of state-of-the-art percutaneous coronary revascularization in patients with de novo three vessel disease: 1-year results of the SYNTAX II study. Eur Heart J 2017;38:3124-34.

85. Maeremans J, Walsh S, Knaapen P, Spratt JC, Avran A, et al. The Hybrid Algorithm for Treating Chronic Total Occlusions in Europe: The RECHARGE Registry. J Am Coll Cardiol 2016;68:1958-70.

86. Kufner S, Joner M, Thannheimer A, Hoppmann P, Ibrahim T, et al. Ten-year clinical outcomes from a trial of three Limus-eluting stents with different polymer coatings in patients with coronary artery disease. Circulation 2019;139:325-33.

87. Barner HB, Standeven JW, Reese J. Twelve-year experience with internal mammary artery for coronary artery bypass. J Thorac Cardiovasc Surg 1985;90:668-75. 